\title{
Are adrenaline autoinjectors fit for purpose? A pilot study of the mechanical and injection performance characteristics of a cartridge- versus a syringe-based autoinjector
}

\author{
This article was published in the following Dove Press journal: \\ Journal of Asthma and Allergy \\ 24 November 2010 \\ Number of times this article has been viewed
}

\author{
Andreas Schwirtz \\ Harald Seeger \\ Pharma Consult GmbH, \\ Vienna, Austria
}

Correspondence: Andreas Schwirtz Pharma Consult $\mathrm{GmbH}$, Research and Development, Divischgasse 4, A-1210, Vienna, Austria

Tel $+43 \quad 129107669$

Fax +43 I29|076377

Email a.schwirtz@bmgrp.at
Background: Adrenaline autoinjectors (AAIs) are prescribed to facilitate the intramuscular administration of adrenaline in patients diagnosed with life-threatening anaphylaxis. This pilot study investigated the injection and functional properties of two AAIs (deploying different delivery systems) under standard conditions, after dynamic and mechanical stresses, and in the presence of denim.

Methods: The differences between a cartridge-based AAI (EpiPen ${ }^{\circledR}$ Junior) and a syringe-based AAI (Anapen ${ }^{\circledR}$ Junior) were assessed using three sets of tests. Test 1: under standard conditions, the injection depth and dose were measured in ballistic gelatine (a validated tissue simulant). Test 2: before the safety cap removal and activation forces were measured, AAIs were subjected to either of two preconditioning tests: 1) free-fall drop test; or 2) static load (ie, $400 \mathrm{~N}$, equivalent to $40 \mathrm{~kg}$ weight) test; or 3 ) no preconditioning. Test 3 : under standard conditions, injection properties into ballistic gelatine in the presence and absence of denim were investigated. Statistical analyses were performed using the Student's $t$-test or Welch's test.

Results: The maximum depth of delivery was significantly greater with cartridge AAI $(n=4$, mean $21.09 \pm 2.54 \mathrm{~mm})$ than with syringe AAI $(\mathrm{n}=5$; mean $11.64 \pm 0.80 \mathrm{~mm} ; P=0.003)$. After 2.5 seconds, cartridge AAI $(n=4)$ discharged significantly more dose than syringe AAI $(n=3$; $74.3 \%$ versus $25.7 \%$ of total dose; $P=0.001$ ). Both cartridge and syringe AAI withstood the free-fall drop test, but almost all devices failed to activate following the static load test. Under standard conditions, significantly less force was required to remove the safety cap of cartridge AAI than syringe AAI (both $\mathrm{n}=15$; mean $9.56 \pm 2.36 \mathrm{~N}$ versus $20.23 \pm 6.61 \mathrm{~N}$, respectively; $P<0.001$ ), but a significantly greater activation force was required for cartridge AAI than syringe AAI (mean $23.01 \pm 3.96 \mathrm{~N}$ versus $8.06 \pm 0.51 \mathrm{~N}$, respectively; $P<0.001$ ). The presence of denim did not alter the activation force or effective needle length of either of the AAIs.

Conclusion: Cartridge AAI appears significantly more capable of consistently and rapidly delivering a clinically relevant dose of intramuscular adrenaline than syringe AAI. However, both devices showed shortcomings in their ability to sustain mechanical stress similar to that which is likely over their shelf life, and as such, may not be fit for life-saving purpose.

Keywords: anaphylaxis, intramuscular, delivery system, device

\section{Background}

Rapid intramuscular (i.m.) adrenaline administration is the acknowledged first-line therapy for the emergency treatment of anaphylaxis, in both hospital and community settings. ${ }^{1-3}$ Because most anaphylactic reactions occur outside of a health care setting, ${ }^{4}$ adrenaline autoinjectors (AAIs) are widely prescribed to patients diagnosed with 
anaphylaxis or those who are at serious risk of anaphylaxis as a result of their allergic status. The AAI should be carried by the patient at all times, providing immediate access to adrenaline during an acute anaphylactic attack, when emergency medical care is otherwise unavailable.

Worryingly, there is significant anecdotal evidence and safety data to suggest that AAIs do not always perform adequately and can misfire. ${ }^{5-7}$ The design of currently available AAIs has not changed significantly in decades. Although the original AAI, EpiPen ${ }^{\circledR}$ - a cartridge-based system - was deemed suitable to ensure the force of injection was sufficient to achieve i.m. penetration, Anapen ${ }^{\circledR}$ (based on a design developed by Owen Mumford named Autoject Mini $^{\circledR}$ ) deploys a syringe-based modified insulin injection device, originally designed for subcutaneous administration of insulin for use in elective situations. Therefore, it is surprising that there are no criteria currently in place, including International Organization of Standards or other regulatory requirements, ${ }^{8}$ to benchmark the performance of AAIs under standard conditions - as there are for insulin peninjectors $^{9}$ - nor tests in routine use to measure the potential effects of everyday wear and tear on AAIs.

This pilot study investigated the functionality and robustness of two currently available AAIs in Europe that deploy different drug delivery systems: EpiPen ${ }^{\circledR}$ Junior (referred to herein as cartridge AAI) and Anapen ${ }^{\circledR}$ Junior (referred to herein as syringe AAI). The main objectives of this study were to assess the differences between the two delivery systems in terms of the injection depth and dose delivered into ballistic gelatine, and to determine the effects of a free-fall drop test, static load test, and the presence of denim on the performance of these devices.

\section{Methods}

In this study, the two AAI devices used for testing were designated cartridge AAI (EpiPen ${ }^{\circledR}$ Junior containing $0.15 \mathrm{mg}$ adrenaline; batch numbers 0000105507 and 0000106991 ; ALK-Abelló, Berkshire, UK) and syringe AAI (Anapen ${ }^{\circledR}$ Junior containing $0.15 \mathrm{mg}$ adrenaline; batch GWR 26122010; Lincoln Medical Ltd, Salisbury, UK), reflecting the type of delivery system deployed.

Several performance tests were carried out: an injection test, to assess the requirement of AAIs to deliver an i.m. injection of adrenaline; a stress test, to determine the ability of the AAIs to resist breakage or malfunction due to the application of eccentric force or falls; and an effective needle-length test, to evaluate the consistency of the AAIs to perform under standard conditions and in a 'real-world' model by injection through denim.
In the first round of tests, 15 of each of the AAIs were subjected to several tests to examine the injection properties (ie, injection depth [in ballistic gelatine], injection dose as measured by the volume injected into ballistic gelatine, and effective needle length [in air]). Effective needle length reflects the potential depth of penetration of the needle itself; for example, a needle that is bent or kinked may not achieve the same depth of injection as a straight needle, which may in turn affect the injection properties or results.

In the second round of tests, 45 of each of the AAIs were subjected to one of three conditions: 1$)$ preconditioning - freefall drop $(n=15), 2)$ preconditioning - static load $(n=15)$, or $3)$ no preconditioning - room temperature and standard atmospheric pressure (ie, control; $\mathrm{n}=15$ ), followed by a series of functionality tests to examine the safety cap removal force and activation force. The two preconditioning tests, free-fall drop test and static load test, were used to mimic real-life situations of being dropped and sat/stood on, respectively.

In the last round of tests, 10 of each of the AAIs were subjected to a series of tests to measure activation force and effective needle length after activation into ballistic gelatine in the presence or absence of denim.

\section{Injection test}

Injection depth

The depth of the injected solution into ballistic gelatine (a validated tissue simulant $)^{10,11}$ was tested by analysing a series of photographs taken for up to 10 seconds ( \pm 0.5 seconds) after activation, using an application programmed in Matlab ${ }^{\odot}$ (version R2008A; The Mathworks Inc., Natick, MA). To visualize the ejected volume, the transparent medication in each device was colored with $0.05 \mathrm{~mL}$ of ink. Due to variations in device construction, a different preparation method for each of the two devices was adopted (see Figure 1). Instead of $0.3 \mathrm{~mL}( \pm 10 \%)$ transparent medication in the unprepared device, the total quantity of colored solution was $0.35 \mathrm{~mL}$ $( \pm 20 \%)$ in the prepared test devices.

The maximum injection depth reached is a composite of the actuating position (affected by the force being applied by the operator to activate only the cartridge device, thereby compacting subcutaneous tissue), effective (exposed) needle length, and injection depth of the medication (as measured in the ballistic gelatine).

\section{Injected dose, as measured by injected volume over time (in ballistic gelatine)}

By assessing key timepoints over the filmed sequence, the two-dimensional area of the injected solution was analyzed using a Matlab application. For each frame of the sequence, 


\section{(A) Cartridge AAI}

Step 1: A $6 \mathrm{~mm}$ hole was drilled through the outer housing of the pen.

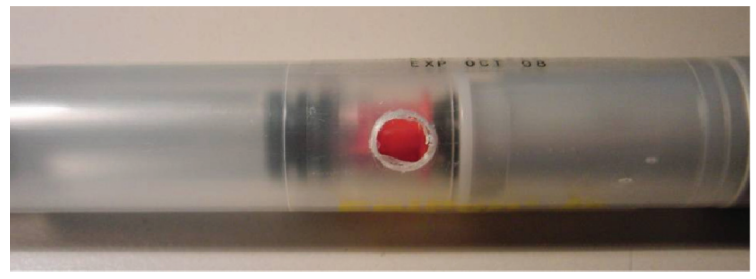

Step 2: $0.5 \mathrm{~mL}$ ink was injected sideways through the plunger stopper via a needle (25G needle) and syringe.

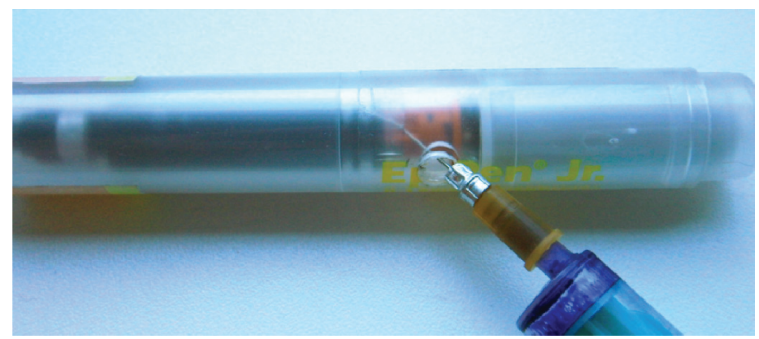

Step 3: The volume of added ink was confirmed by weighing the device before and after filling.

\section{(B) Syringe AAl preparation}

Step 1: The needle/protection cap was removed and $0.5 \mathrm{~mL}$ ink was injected via a needle (22G needle that fits over the $27 \mathrm{G}$ needle of the syringe AAI) and syringe.

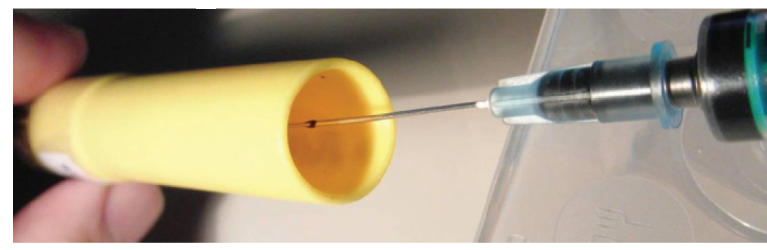

Step 2: The volume of added ink was confirmed by weighing the device before and after filling.

Figure I Preparation of cartridge $\mathrm{AAI}(\mathbf{A})$ and syringe AAI (B) devices for the ballistic gelatine test. Abbreviation: AAI, adrenaline autoinjector.

the area of the colored medication was converted into pixels by digital image processing. Based on the number of pixels, the injected dose was calculated.

\section{Key device properties measured and noted}

After testing of the activation force, the effective needle length as determined by the exposed needle using a caliper, and the diameter of the needle bore, were noted.

\section{Preparation of the ballistic gelatine blocks}

Ballistic gelatine has been used as a tissue simulant for research purposes since the $1960 \mathrm{~s}^{10,11}$ The ballistic gelatine blocks were prepared according to the manufacturer's instructions (Gelita Gelatine, Typ Ballistic 3; Lot: 73211). A plastic box (transparent polypropylene; $60 \mathrm{~mm} \times 60 \mathrm{~mm}$ ) was filled with the gelatine fluid $(170 \mathrm{~mL})$, and stored for a minimum of 48 hours at $4^{\circ} \mathrm{C}$. Because the temperature of 
the gelatine may affect its hardness, all blocks were stored at room temperature and standard pressure for at least 24 hours before use. The hardness of each gelatine block was checked and described using the Bloom index (score range 50-300), confirming that the tests were performed with similar blocks. In order to avoid damage to the surface of the gelatine by autoinjectors that have a higher activation force, a top layer of a $0.5 \mathrm{~mm}$ polypropylene foil (with a small $2 \mathrm{~mm}$ central hole) was placed on top of each ballistic cube.

\section{Preconditioning - stress tests Dynamic impact (free-fall drop test)}

To assess the robustness of the device, and to mimic real-life situations of accidentally dropping the device, each brand of autoinjector was subjected to the drop test. The devices were dropped three times in free fall from a height of $1 \mathrm{~m}$ onto a hard, concrete plate, once horizontally and twice vertically, the autoinjector being rotated between the two vertical drops. In order to standardize the test process, the autoinjectors were guided by a plastic pipe.

\section{Static load}

To mimic real-life situations such as accidentally sitting or stepping on the device, both autoinjectors were subjected to the static load test. Each autoinjector was secured vertically onto the Zwick equipment (Zwick GmbH \& Co, Ulm, Germany) via an adapter before a static weight of $400 \mathrm{~N}$, equivalent to $40 \mathrm{~kg}$ (ie, the approximate weight of a child), was automatically loaded for 10 seconds.

\section{Functionality tests}

\section{Safety cap removal force}

Inherent within the design of syringe AAI are two caps: 1) a protection cap (that covers the needle) and 2) a safety cap (that prevents accidental firing); whereas the cartridge AAI only has one cap (a safety cap). Therefore, syringe AAI requires an extra operational step to remove both caps before the device can be activated, compared with cartridge AAI.$^{12}$ It is important that the safety cap can still be removed easily and without extra force after it has been dropped or when a load has been applied. In this study, the force required to pull off the caps was tested and compared using Zwick ${ }^{\odot}$ equipment (Type: BT01FRO.5TND.14; serial no: 185124/2008; Zwick Roell) and a specially designed adapter to hold the cap (see Figure 2).

\section{Activation force}

In real-life situations, the technique required to activate cartridge AAI is different from that required for syringe
AAI (ie, a swinging activation versus thumb activation, respectively). However, in this study, both autoinjectors were activated using the same methodology. After each of the autoinjectors was secured vertically onto the Zwick equipment (via exchangeable adapters that incorporated the different cartridge- or syringe-based systems), the device was activated - ejecting the medication in air or, in the case of the denim series of experiments, into ballistic gelatine placed at the bottom of the equipment - and the activation force recorded.

\section{Effect of denim on activation force and effective needle length}

Secured vertically onto the Zwick equipment via an adapter, each autoinjector was fired into ballistic gelatine in the presence or absence of a piece of denim (a double seam of Levi's blue jeans). The activation force was recorded, and the effective (exposed) needle length was measured by a caliper after the device was removed from the ballistic gelatine. In addition, the exposed needle was inspected visually.

\section{Statistical analyses}

Data were described as mean \pm standard deviation. Due to the number of test devices assessed in this pilot study, intergroup differences were compared using the $t$-test or the Welch's test (safety cap removal and activation force; injection depth and delivered dose, as appropriate depending on the statistical preconditions, with statistical significance when $P<0.05)$.

\section{Results}

\section{Injection depth and dose delivered - standard conditions}

\section{Effect on injection depth}

Under standard conditions, the maximum injection depth of cartridge AAI $(\mathrm{n}=4$; mean $21.09 \pm 2.54 \mathrm{~mm})$ was significantly greater than syringe AAI $(n=5$; mean $11.64 \pm 0.80 \mathrm{~mm} ; P<0.001$ ) (see Figures 3 and 4).

\section{Injection dose (into ballistic gelatine)}

After 2.5 seconds, cartridge AAIs had discharged significantly more dose $(n=4$; mean $0.26 \pm 0.04 \mathrm{~mL}[74.3 \%$ of total dose]) than syringe AAIs ( $\mathrm{n}=3$; mean $0.09 \pm 0.02 \mathrm{~mL}$ [25.7\% of total dose]; $P<0.01$ ) (see Figure 5). Although patients are instructed to hold the AAI for 10 seconds after device activation, results from this study show that with cartridge AAI, the mean injection volume had plateaued after just 2.5 seconds, but not with syringe AAI (data not shown). 
A)

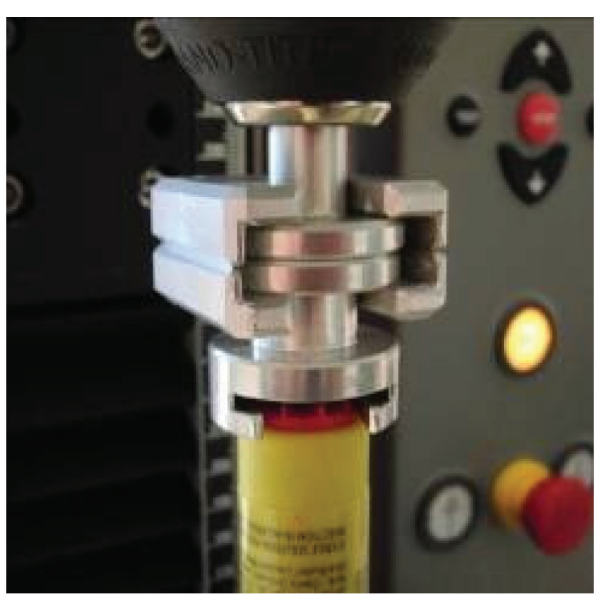

B)

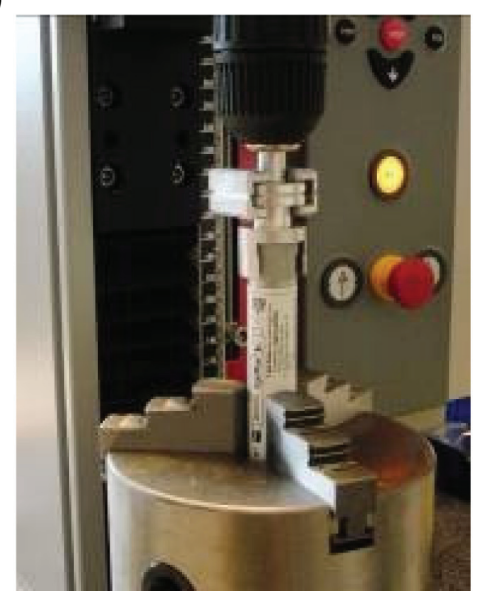

C)

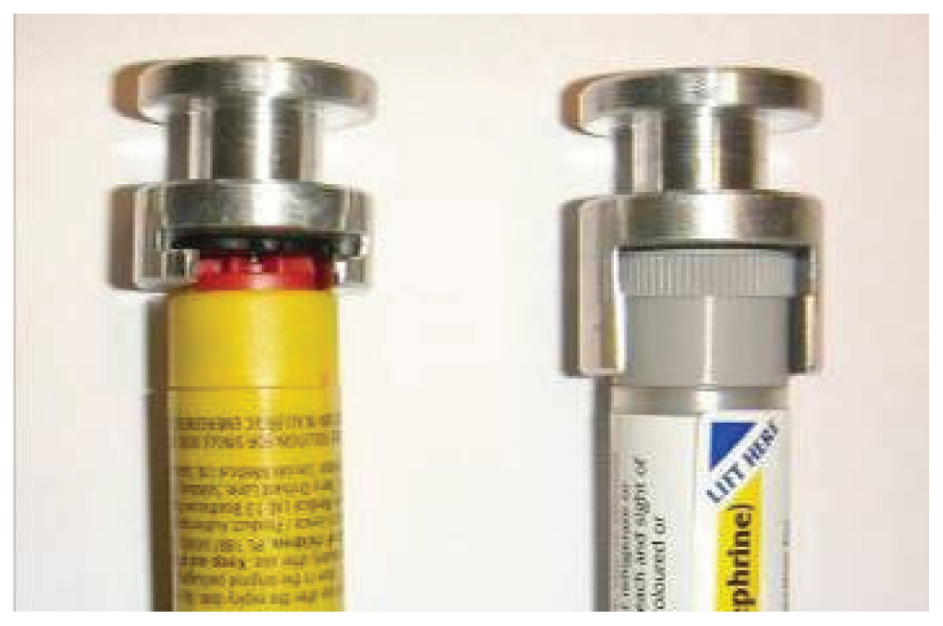

Figure 2 The Zwick ${ }^{\odot}$ equipment measuring the safety cap removal force of syringe adrenaline autoinjector (AAI) (A) and cartridge AAI (B) with the specially designed adapter (C).

Physical properties of layered gelatine blocks hampered interpretation of data beyond 2.5 seconds, as this was the timepoint at which maximum delivery of dose was achieved with syringe AAI (Figure 4).

\section{Effective needle length and needle bore diameter}

Under standard conditions, the mean effective needle length of cartridge AAI after activation was significantly longer than syringe AAI (both $\mathrm{n}=15 ; 13.13 \pm 0.208 \mathrm{~mm}$ and $8.02 \pm 0.769 \mathrm{~mm}$, respectively; $P<0.001)$, and the needle bore diameter is larger (ie, 22 gauge versus 27 gauge needles, respectively) (see Figure 6).

\section{Effect of preconditioning}

Overall, the preconditioning tests demonstrated that both cartridge AAI and syringe AAI were able to withstand a free-fall drop test from $1 \mathrm{~m}$ onto concrete, although in one free-fall test with cartridge AAI front ahead, the device was rendered nonsterile, as the needle pierced through the rubber cap and the needle tip was damaged (Table 1). However, neither of the AAIs was able to withstand the static load test, as signs of damage to the outer housing on visual inspection were noted (Table 1).

\section{Effect on safety cap removal force}

Under control conditions (ie, without preconditioning), no significant difference was found between the removal force of the protection cap and the safety cap of syringe AAI $(P=0.08)$. Therefore, only the removal force of the safety cap for syringe AAI has been used in subsequent comparisons. When comparing the safety cap removal force, significantly less force was required to remove the cartridge 


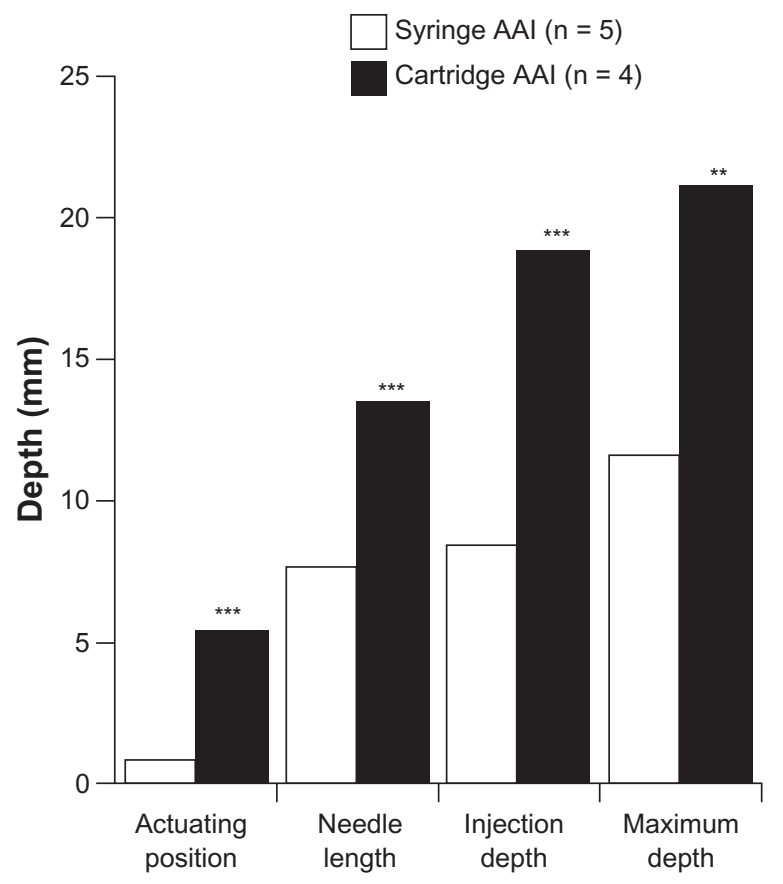

Figure 3 Comparison of maximum depth components for each device group under standard conditions.

Note: ${ }^{* * *} P<0.01$ vs syringe AAl, ${ }^{* * 0} P<0.001$ vs syringe AAl

Abbreviation: AAI, adrenaline autoinjector.

AAI safety cap than the syringe AAI safety cap $(P<0.001)$ (see Table 2).

After preconditioning with a free-fall drop test, the mean safety cap removal force for both autoinjectors was not altered significantly compared with its respective controls (Table 2). However, after preconditioning with a static load, the mean safety cap removal force for cartridge AAI was increased approximately fourfold $(P<0.001)$, whereas there was no significant change with syringe AAI $(P=0.633)$ (see Table 2).

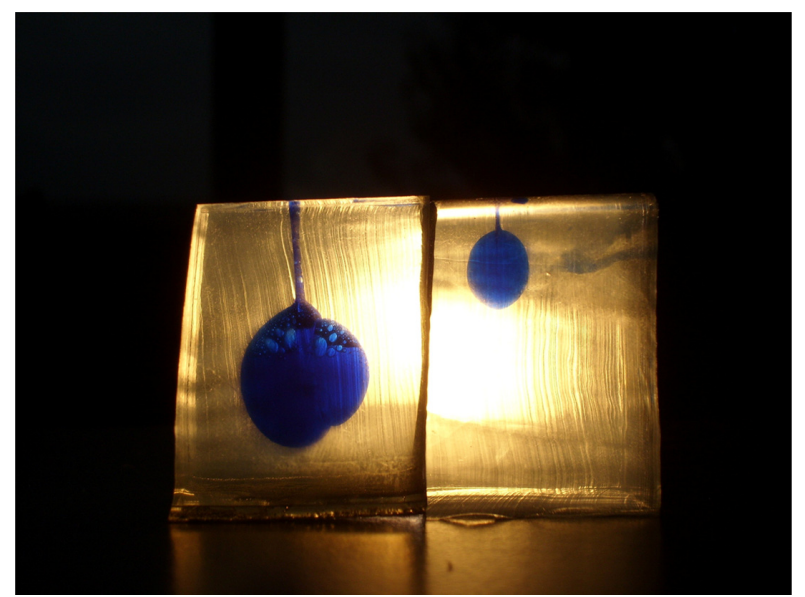

Figure 4 Example photograph showing the difference in injected dose and overall injection depth into ballistic gelatine (left, cartridge adrenaline autoinjector [AAI]; right, syringe $A A I)$.

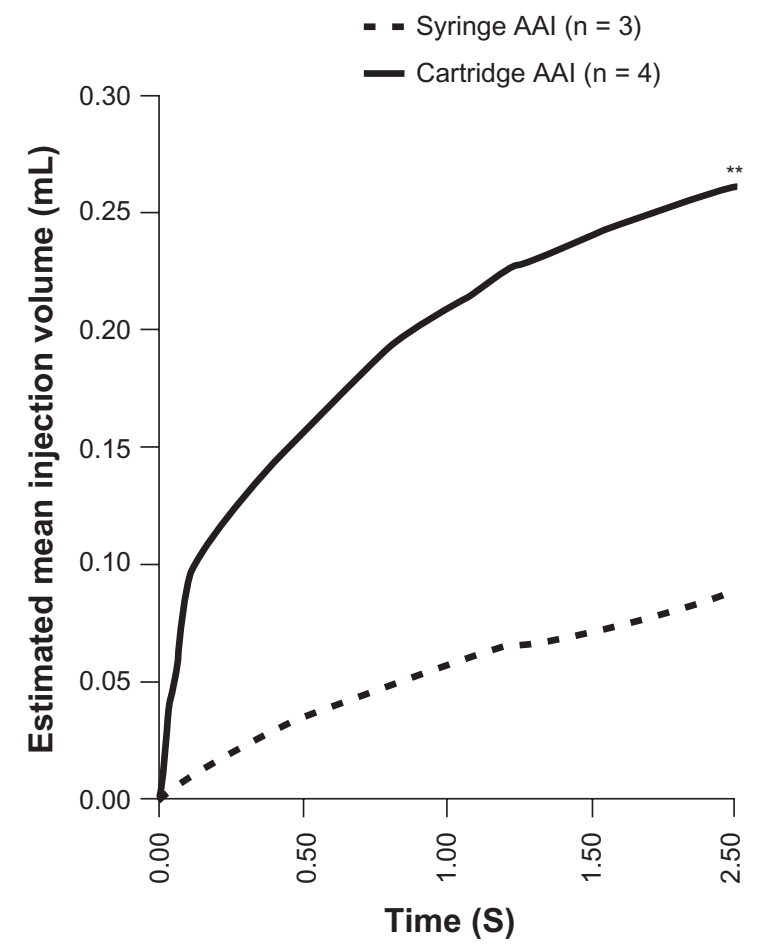

Figure 5 Mean volume injected during the first 2.5 seconds after activation. Note: **P $<0.01$ vs syringe $\mathrm{AAl}$ at $2.5 \mathrm{~S}$

Abbreviation: AAI, adrenaline autoinjector.

\section{Effect on activation force}

Without preconditioning, the activation force for cartridge AAIs ( $\mathrm{n}=15$; hand activation) was greater than for syringe AAIs ( $\mathrm{n}=15$; thumb activation) (mean $23.01 \pm 3.96 \mathrm{~N}$ versus $8.06 \pm 0.51 \mathrm{~N}$, respectively; $P<0.001)$. After preconditioning with a free-fall drop test, the mean activation force for cartridge AAI $(n=14)$ remained greater than for syringe AAI $(\mathrm{n}=15 ; 22.55 \pm 5.14 \mathrm{~N}$ versus $8.65 \pm 0.63 \mathrm{~N}$, respectively;

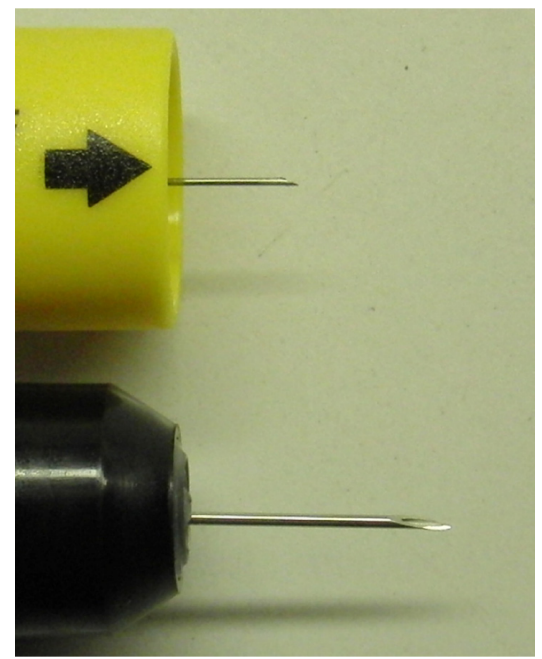

Figure 6 Photograph of exposed 'effective' needle after activation (upper, syringe adrenaline autoinjector [AAI]; lower, cartridge AAI). 
Table I Effect of free-fall and static load tests

\begin{tabular}{|c|c|c|c|}
\hline Drop test & $\begin{array}{l}\text { Fully intact } \\
\text { (n) }\end{array}$ & $\begin{array}{l}\text { Broken internal components } \\
\text { (n) }\end{array}$ & $\begin{array}{l}\text { Damaged needle } \\
\text { (n) }\end{array}$ \\
\hline Syringe AAI & 15 & 0 & 0 \\
\hline Cartridge AAI & 14 & 0 & I \\
\hline Static load test & $\begin{array}{l}\text { Fully intact } \\
\text { (n) }\end{array}$ & $\begin{array}{l}\text { Outer housing broken } \\
\text { Activation not achieved } \\
\text { (n) }\end{array}$ & $\begin{array}{l}\text { Outer housing broken } \\
\text { Increased activation } \\
\text { force }(n)\end{array}$ \\
\hline Syringe AAI & 0 & 13 & 2 \\
\hline Cartridge AAI & 0 & 15 & 0 \\
\hline
\end{tabular}

$P<0.001)$. However, after preconditioning with a static load of $400 \mathrm{~N}$ in vertical orientation, $100 \%(15 / 15)$ of cartridge AAI and $86.7 \%(13 / 15)$ of syringe AAI devices would not fire. Of the two syringe AAIs that could be activated, the force that was required had increased approximately fivefold compared with control AAIs (data not shown).

\section{Effect of denim on activation force and effective needle length}

Under standard conditions, the mean activation force for cartridge AAIs remained unchanged in the presence of denim $(\mathrm{n}=5 ; 23.48 \pm 3.65 \mathrm{~N}$ compared with $22.43 \pm 4.64 \mathrm{~N}$ in ballistic gelatine only; $P=0.596)$. This was similarly the case for syringe AAIs $(n=5 ; 8.22 \pm 0.60 \mathrm{~N}$ compared with $8.39 \pm 0.66 \mathrm{~N}$ in ballistic gelatine only; $P=0.555$ ).

After device activation into ballistic gelatine and denim, the effective needle length for cartridge AAI and syringe

Table 2 Effect of free-fall test and static load test on safety cap removal force

\begin{tabular}{|c|c|c|c|}
\hline & $\begin{array}{l}\text { Sample } \\
\text { number (n) }\end{array}$ & $\begin{array}{l}\text { Mean } \pm \text { SD } \\
\text { cap removal } \\
\text { force }(\mathbf{N})\end{array}$ & $P$-value \\
\hline \multicolumn{4}{|c|}{ Without preconditioning - standard conditions (control) } \\
\hline $\begin{array}{l}\text { Syringe AAI - } \\
\text { protection cap }\end{array}$ & 20 & $16.58 \pm 5.86$ & - \\
\hline $\begin{array}{l}\text { Syringe AAI - } \\
\text { safety cap }\end{array}$ & 15 & $20.23 \pm 6.61$ & - \\
\hline $\begin{array}{l}\text { Cartridge AAI - } \\
\text { safety cap }\end{array}$ & 15 & $9.56 \pm 2.36$ & $\begin{array}{l}P<0.00 \text { I versus } \\
\text { syringe } A A I- \\
\text { safety cap }\end{array}$ \\
\hline \multicolumn{4}{|c|}{ Preconditioning - free-fall test } \\
\hline $\begin{array}{l}\text { Syringe AAI - } \\
\text { safety cap }\end{array}$ & 15 & $21.07 \pm 1.19$ & $\begin{array}{l}P=0.690 \text { versus } \\
\text { control }\end{array}$ \\
\hline $\begin{array}{l}\text { Cartridge AAI - } \\
\text { safety cap }\end{array}$ & 15 & $9.98 \pm 0.68$ & $\begin{array}{l}P=0.653 \text { versus } \\
\text { control }\end{array}$ \\
\hline \multicolumn{4}{|c|}{ Preconditioning - static load test } \\
\hline $\begin{array}{l}\text { Syringe AAI - } \\
\text { safety cap }\end{array}$ & 15 & $18.89 \pm 2.203$ & $\begin{array}{l}P=0.633 \text { versus } \\
\text { control }\end{array}$ \\
\hline $\begin{array}{l}\text { Cartridge AAI - } \\
\text { safety cap }\end{array}$ & 15 & $38.39 \pm 1.458$ & $\begin{array}{l}P<0.00 \text { I versus } \\
\text { control }\end{array}$ \\
\hline
\end{tabular}

AAI was not significantly different compared with ballistic gelatine alone $(P=0.290$ and $P=0.995$, respectively; data not shown).

Visual inspection of the needle after removal from the ballistic gelatine after activation showed no damage or bending of the needle for syringe AAI. However, the needles from three cartridge AAIs (two from the ballistic gelatine + denim test and one from ballistic gelatine alone) were bent between $5^{\circ}$ and $10^{\circ}$.

\section{Discussion}

To summarize, compared with the syringe-based AAI, the cartridge-based system of autoinjection appears significantly more capable of consistently and rapidly delivering a clinically relevant dose to the desired i.m. region, through a combination of higher activation force, higher extrusion force and wider needle bore.

Under standard conditions, the force required to remove the safety cap from cartridge AAI was significantly less than that required for syringe AAI. The mean safety cap removal force was not changed for both AAIs following the free-fall drop test, although the static-load test resulted in a fourfold increase in the safety cap removal force of cartridge AAI. The activation force for cartridge AAI was significantly higher than that for syringe AAI prior to and following the free-fall drop test. A high activation and spring force for cartridge AAIs should ensure that a sufficient dose is delivered to the correct tissue compartment (i.m.) because of the resultant higher subcutaneous tissue compression and extrusion force. These forces may be inherently limited in the design of syringe AAIs through a combination of weaker points in the glass syringe, lower activation force and the different activation technique required (ie, no swinging action) compared with cartridge AAIs. Thus, a lower activation force observed with syringe AAI may make the device easier to use, but could mean it is less sufficient in delivering an effective dose, as demonstrated in this study. However, to the best of our knowledge, there is currently no evidence 
to suggest that this occurs in clinical practice or in real-life emergency situations.

The essential clinical feature of an AAI is the ability to reliably deliver a full i.m. dose of adrenaline after being carried by the patient and subjected to mechanical stress over the shelf life of the AAI. Data from this pilot study showed that both cartridge and syringe AAI were able to withstand the free-fall drop test. However, a static load equivalent to $40 \mathrm{~kg}$ resulted in damage not only to the outer housing of both types of device but more importantly also damaged the activation mechanism causing the vast majority to fail (100\% of cartridge AAI and $86.7 \%$ of syringe AAI devices would not fire). The inconsistent results obtained after the static load test raises concerns regarding the reliability of cartridge AAIs, particularly with regards to the ability of the casing (outer housing) to withstand the stresses of modern living. The fact that the casings of both device types were damaged after a static load was applied suggests that there is a requirement for the use of stronger plastic materials in AAIs that do not go brittle over time, or a more robust design, as the AAIs must remain functional over the lifetime of the product and under all conditions. Because damage to the device may only be visible to a trained eye, it would normally only be revealed in a real-life situation, when a patient tries to administer adrenaline in an emergency, with potentially fatal consequences. Therefore, the use of additional carrying cases, such as the transparent plastic tube supplied with EpiPen ${ }^{\circledR}$ devices along with their cardboard cartons, may also provide greater protection than the sole cardboard carton packaging of Anapen ${ }^{\circledR}$ devices.

A final requirement of AAIs is the capacity to inject into the i.m. compartment through clothing. The presence of denim did not affect the mean activation force or the effective needle length of either device in this study. However, some needles of cartridge AAIs were bent after activation into ballistic gelatine, in the presence or absence of denim. The effect of a bent needle on the delivery of adrenaline into the correct tissue compartment requires further investigation.

Cartridge AAI also had a longer effective needle length than syringe AAI, and therefore is more likely to deliver to the correct i.m. tissue compartment. However, needle length alone is not sufficient to judge i.m. injecting ability in clinical practice, ${ }^{13}$ especially in the case of an obese patient with excess subcutaneous fat, or a patient wearing thick clothing. In addition, given the nature of these devices, it may be possible that devices with longer needles are not suitable for and are less likely to be used by small children.
It is important to note that the model used in this pilot study is a simplified simulation of clothed patients in the realworld setting. Other limitations of this pilot study include: the small sample size used in some tests; the unknown effect of adding $16.6 \%$ extra volume of ink into the adrenaline solution of each device; the fact that these devices were no longer tamper-free (although the techniques adopted involved minimal tampering); the disadvantages of ballistic gelatine as a simulator of human tissue; the dose delivered was only measured over 2.5 seconds and not over 10 seconds as per the patient instructions for both AAIs (in order to avoid bias because the physical properties of layered gelatine blocks hampered interpretation of data beyond this timepoint).

The data presented here indicate that there are significant limitations in the design and quality of current AAIs available for the treatment of life-threatening anaphylaxis. Based on these small-scale tests, there is sufficient concern over the performance of the AAIs - in particular syringe AAIs - to call for a larger, more in-depth study including all devices, a variety of tissue simulants (including pig cadaver), threedimensional analysis to evaluate injection depth and ultimately the development of standardized, validated assessment criteria of these putatively life-saving devices.

\section{Conclusion}

Data from this pilot-study, investigating the 'real-world' functionality and robustness of two currently available AAIs, indicate that cartridge AAI appears significantly more capable of consistently delivering a quick clinically relevant dose of i.m. adrenaline than syringe AAI. The syringe-based delivery system has inbuilt design limitations potentially making their dose delivery suboptimal. However, both cartridge and syringe AAIs are associated with shortcomings following mechanical stress similar to that which is likely for the duration of their shelf life, and as such, may not be fit for lifesaving purpose. The findings from this study indicate a need for larger, more in-depth studies of the performance of AAIs, together with the development of standardized, validated assessment criteria for these devices.

\section{Competing interests}

The authors declare that they have no competing interests.

\section{Authors' contributions}

AS and HS participated in the design of the study, and HS performed the statistical analysis. AS conceived of the study, participated in its design and coordination, and reviewed and 
helped to draft the manuscript. All authors read and approved the final manuscript.

\section{Acknowledgments}

Pharma Consult $\mathrm{GmbH}$ provided funding for this study. The authors would like to thank Markus Csenar for his creative inputs regarding the test settings, Natalia Gadek for her support with the statistical analyses, and Ewald Pickhard for his consultancy with 30 years' experience in the field of autoinjector technology (all from Pharma Consult). They would also like to thank Quyen Chu, $\mathrm{PhD}$ (a member of the European Medical Writers Association) who provided medical writing and editorial support.

\section{References}

1. Muraro A, Roberts G, Clark A, et al; for the EACCI Task Force on Anaphylaxis in Children. The management of anaphylaxis in childhood: a position paper of the European academy of allergology and clinical immunology. Allergy. 2007;62:857-871.

2. Sheikh A, Shehata YA, Brown SGA, Simons FER. Adrenaline (epinephrine) for the treatment of anaphylaxis with and without shock (Review) Cochrane Database Syst Rev. 2008;4:CD006312.

3. Resuscitation Council UK. Emergency treatment of anaphylactic reactions. Guidelines for healthcare providers. Available from: http://www. resus.org.uk/pages/reaction.pdf. Accessed 2010 Oct 1.
4. de Silva IL, Mehr SS, Tey D, Tang ML. Paediatric anaphylaxis: a 5 year retrospective review. Allergy. 2008;63:1071-1076.

5. Fitzcharles-Bowe C, Denkler K, Lalonde D. Finger injection with highdose $(1: 1,000)$ epinephrine: does it cause finger necrosis and should it be treated? Hand (NY). 2007;2:5-11.

6. Simons FER, Lieberman PL, Read EJ Jr, Edwards ES. Hazards of unintentional injection of epinephrine from auto-injectors: a systematic review. Ann Allergy Asthma Immunol. 2009;102:282-287.

7. Walker DM. Update on epinephrine (adrenaline) for pediatric emergencies. Curr Opin Pediatr. 2009;21:313-319.

8. Frew AJ. What are the 'ideal' features of an adrenaline (epinephrine) auto-injector in the treatment of anaphylaxis? Allergy. Epub 2010 Aug 17.

9. International Organization for Standardization (ISO). ISO 11608-1:2000. Pen-injectors for medical use. Part 1: pen-injectors - requirements and test methods. Available from: http://www.iso.org/. Accessed 2010 Oct 1.

10. Haiduven D, Applegarth S, DiSalvo H, Mangipudy S, Konopack J, Fisher J. A pilot study to measure the compressive and tensile forces required to use retractable intramusclar safety syringes. Am J Infect Control. 2006;34:661-668.

11. Nicholas NC, Welsch JR. Institute for Non-Lethal Defense Technologies (INLDT) report: ballistic gelatine. State College, PA: Applied Research Laboratory, Pennsylvania State University; 2004;1-20.

12. Davis JE. Self-injectable epinephrine for allergic emergencies. J Emerg Med. 2009;37:57-62.

13. Stecher D, Bulloch B, Sales J, Schaefer C, Keahey L. Epinephrine auto-injectors: is needle length adequate for delivery of epinephrine intramuscularly? Pediatrics. 2009;124:65-70.
Journal of Asthma and Allergy

\section{Publish your work in this journal}

The Journal of Asthma and Allergy is an international, peer-reviewed open-access journal publishing original research, reports, editorials and commentaries on the following topics: Asthma; Pulmonary physiology; Asthma related clinical health; Clinical immunology and the immunological basis of disease; Pharmacological interventions and

\section{Dovepress}

new therapies. Issues of patient safety and quality of care will also be considered. The manuscript management system is completely online and includes a very quick and fair peer-review system, which is all easy to use. Visit http://www.dovepress.com/testimonials.php to read real quotes from published authors. 